\title{
ÉRASE UNA VEZ UN SÍNODO... De los jóvenes, con los jóvenes o para los jóvenes
}

DOI: https://doi.org/10.52039/seminarios.v65i226.22

AlONSO MORATA MOYA*

\section{NOS SITUAMOS}

No hay duda: la convocatoria de un Sínodo que tiene como objetivo situarse de forma nueva ante los jóvenes de hoy con la intención de que sean ellos los que «se presenten» nos digan qué son y cómo se ven, qué perspectiva vislumbran, qué les impulsa en la vida y cuáles son sus resortes en la misma. Estamos, pues, ante una actitud nueva. Porque, si es verdad que los jóvenes necesitan ser evangelizados, resulta igualmente urgente que les trasmitamos con nuestra vida el ejemplo y la dinámica renovadora del seguimiento de Jesús de Nazaret, sin lastres de siglos pasados.

La primera pregunta que me hago es: ¿ha respondido el Sínodo a los interrogantes que hay en el corazón de los jóvenes?

\section{LAS RESPUESTAS DEL SíNOdO}

Es muy interesante que el texto de partida sean palabras que invitan a ver y no a «soportar» una clase teórica. El pasaje lo conocemos todos: Juan, el apóstol, afirma en su evangelio que él no sólo es la figura ejemplar del joven que elige seguir a Jesús, sino también «el discípulo a quien Jesús amaba»: «Fijándose en Jesús que pasaba, [Juan el Bautista] dijo: 'He ahí el Cordero de Dios'. Los dos discípulos le oyeron hablar así y siguieron a Jesús. Jesús se volvió y, al ver que le seguían, les dice: '¿Qué buscáis?'. Ellos le respondieron: 'Rabbí -que quiere decir Maestro-, ¿dónde vives?'. Les respondió: 'Venid y lo veréis'. Fueron, pues, vieron dónde vivía y se quedaron con él aquel día. Era más o menos la hora décima» (Jn 1, 36-39).

Como primera respuesta del Sínodo a los jóvenes está la siguiente: Conoceréis a Jesús si pasáis un día con Él y os dejáis cautivar por su mirada. Después nada os impedirá seguirlo a donde quiera que os lleve. Y es que las

* Párroco de San Cristóbal y San Rafael, Madrid. Director de la revista Seminarios. 
teorías, los bellos relatos, las mismas aventuras, no tienen efecto si no hay una sintonía desde la admiración y el afecto que lleva a descubrir esa nueva forma de amar que significa «darlo todo, darse enteramente». Que esto se puede realizar desde un primer contacto con Jesús, que necesita después la confianza del trato frecuente, que puede pasar por momentos de frialdad y de crisis, es normal, ¿pero hay algo que no se apaga?: el fuego «¿no ardía nuestro corazón cuando nos explicaba las Escritura?». Es importante que cuando descubramos a Jesús que camina a nuestro lado sea porque arde nuestro corazón, porque sentimos la vida nueva en nosotros. Veamos lo que nos dice el número 4 del documento conclusivo del Sínodo:

Jesús camina con los dos discípulos que no han entendido el significado de su historia y se están alejando de Jerusalén y de la comunidad. Para estar en su compañía, recorre el camino con ellos. Les hace preguntas y escucha su versión de los hechos para ayudarles a reconocer lo que están experimentando. Luego, con afecto y energía, les anuncia la Palabra, guiándolos a interpretar. a la luz de las Escrituras los acontecimientos que han vivido. Acepta la invitación para quedarse con ellos al anochecer: entra en su noche. Al escuchar, su corazón se calienta y su mente se ilumina, en la fracción del pan que sus ojos abren. Ellos mismos optan por reanudar el viaje en la dirección opuesta sin demora, para regresar a la comunidad, compartiendo la experiencia del encuentro con el Resucitado.

Esta realidad necesita un proceso, de ahí la importancia del acompañamiento. Jesús sale al camino por donde ellos van. En primer lugar, se acerca, les pregunta, los escucha, quiere que manifiesten el porqué están discutiendo, de su malestar, de su decepción, del abandono de la comunidad. Cuando le cuentan a Jesús su estado de ánimo, su desmoronamiento porque lo que esperaban no ha sucedido, el viajero se pone a enseñarles, les conduce para que ellos descubran que lo ocurrido era el plan de Dios para salvar a los hombres y, en el corazón de ellos que viven una negra y desorientada noche, surge una luz, luz que se va haciendo más iluminadora hasta que la fracción del pan les descubre quien es aquel que los ha acompañado todo ese tiempo. La noche ha desaparecido de su corazón y emprenden el camino de vuelta a la comunidad.

¡Qué importante es que, mediado el acompañamiento, nuestros jóvenes se incorporen a la comunidad y sean revulsivo para la renovación de la misma! Del pasaje que hemos citado toma el redactor del documento el esquema a seguir:

-La primera parte se titula «Él caminó con ellos» (Lc 24,15), y busca iluminar lo que los Padres sinodales reconocieron en el contexto en el que se insertan los jóvenes, destacando sus fortalezas y desafíos. 
-La segunda parte, «Sus ojos fueron abiertos» (Lc 24, 31), es interpretativa y proporciona algunas claves fundamentales del tema del Sínodo.

- La tercera parte, titulada «Se fueron sin demora» (Lc 24, 33), recoge las opciones para una conversión espiritual, pastoral y misionera.

Pero me gustaría resaltar la actitud de escucha del Señor, porque no es posible que el joven escuche si no ve interés en el interlocutor por la realidad de su vida, si no descubre que aquel no se le acerca como maestro que viene a advertirle, sino como alguien que se interesa por su vida, por sus problemas reales, por las situaciones negativas y positivas, por sus fuerzas y sus necesidades de ayuda, en una palabra para acompañar el tiempo y el modo que el joven necesite de su compañía para avanzar en su fe, su compromiso, su elección de vida.

Esos pasos son los que da Jesús en el acompañamiento que hace de los dos de Emaús (se hace el encontradizo, camina con ellos y se mete en la conversación que traen, les abre los ojos, hace que arda el corazón, recuperan la luz y vuelven sin tardanza, corren a incorporarse a la comunidad). Siempre me ha llamado la atención el hecho de que, una vez se les abren los ojos, cuando su presencia no es necesaria, Jesús desaparece.

Pero es que esa es la postura del acompañante: ir con el acompañado hasta el momento en el que no necesite su presencia y ayuda para descubrir cuál es su camino. Porque hay acompañantes que se empeñan en no soltar a la persona que, ya madura en algunos aspectos, necesita de acompañante diferente. Una de las grandes cualidades del orientador es saber desaparecer en el momento oportuno. Los jóvenes de hoy necesitan un acompañamiento, pero no un atosigamiento. El desprendimiento es rasgo base en una persona que ayuda a otra en su camino y sabe dejarle libre a tiempo.

La escucha hace posible intercambiar regalos en un contexto de empatía. Les permite a los jóvenes donar su contribución a la comunidad, ayudándolos a captar nuevas sensibilidades y hacer preguntas no publicadas. Al mismo tiempo, establece las condiciones para un anuncio del Evangelio que verdaderamente llegue al corazón, de una manera incisiva y fructífera (Conclusiones Sínodo, 8, § 2).

Una de las carencias de nuestra sociedad es la atención al otro, el situarnos en la perspectiva que tiene el otro para entender lo que nos dice: carecemos de sentido de la escucha, siendo esta un medio único para la comprensión, el entendimiento, la superación de la dictadura de la palabra, la imposición de lo correcto socialmente que, a veces, puede ser muy dañino, sobre todo porque elimina la empatía que facilita la progresión en la 
conversación y en la acción. En lo referente a la comunicación de la Buena noticia, esta actitud abierta, ayuda a que sea luz para la sociedad actual y pueda ser percibida.

\begin{abstract}
Escuchar es un momento calificativo en el ministerio de pastores y, en primer lugar, en los obispos, que a menudo se sienten agobiados por muchos compromisos y luchan por encontrar el tiempo adecuado para este servicio indispensable. Muchos han notado la falta de expertos y dedicados al acompañamiento. Creer en el valor teológico y pastoral de escuchar implica un replanteamiento para renovar las formas con que normalmente se expresa el ministerio presbiteral y una verificación de sus prioridades. Además, el Sínodo reconoce la necesidad de preparar laicos consagrados, hombres y mujeres, que estén calificados para el acompañamiento de los jóvenes. El carisma de escucha que el Espíritu Santo da lugar en las comunidades también podría recibir una forma de reconocimiento institucional para el servicio eclesial.
\end{abstract}

A la escucha debe seguir el verdadero diálogo. En su etimología, la palabra diá-logos evoca la participación de dos y, por tanto, un cierto «consenso», o sea, que se busque llegar a un lenguaje común para ambos interlocutores. Esto exige un introducirse en la comprensión del lenguaje nuevo, del significado y el alcance de cada una de las palabras: situarse en la misma perspectiva. Emisor y receptor (intercambiables en el diálogo) han de partir de una misma calidad del lenguaje.

\title{
2. EL VALOR DE LA ESCUCHA
}

Sintonicemos una emisora (de radio o televisión), analicemos las actitudes de los intervinientes en un diálogo. Pronto aprenderemos en qué consiste el ejercicio de «no escuchar», «no dialogar». Nos damos cuenta enseguida de que cada uno de ellos lleva su discurso bien preparado y no atiende a la posibilidad de que el otro le haga cambiar de idea, contemplar 0 escuchar las diversas opiniones. Además, se interrumpen unos a otros, no toman en consideración el punto de vista del que está a su lado.

Sin embargo, esta no puede ser la actitud de hombre de Iglesia, sobre todo en lo que concierne a ese esencial acto del ministerio que es el acompañamiento. En él se exige escuchar (prestar atención para captar la situación de cada acompañado, para no hablar en ni de teorías, sino asentarse en la realidad que envuelve la vida de aquel a quien tienes que acompañar). Algo muy importante es que el acompañante sepa que no es alguien que siempre ha de estar en la dinámica de vida del acompañado. Difícilmente nos situaremos a la escucha, si no abrimos nuestro discurso a la posición del interlocutor. 
En la dinámica de la fe, hay siempre un diálogo abierto. Es verdad que la identidad del interlocutor que llama puede hacer que uno se sienta sobrecogido (y es normal), pero hay una cosa segura en el diálogo de Dios con el hombre: Dios siempre acepta el conversar con el llamado. Solo tenemos que acercarnos a tantos textos de llamada que aparecen en la Sagrada Escritura, entre ellos los del Antiguo Testamento. Si es verdad que la reacción primera es de cierto temor, la sorpresa de que Dios se acerque a nosotros siempre es grande, pero el gozo por la confianza depositada es mayor que ese inicial temor (Abrahán, Moisés, Elías, los profetas) sienten una gran alegría al comprobar que la misión que se les confía tiene el respaldo del mismo Dios.

La fe, en cuanto participación en el modo de ver de Jesús (cf. Lumen fidei 18), es la fuente del discernimiento vocacional, porque ofrece sus contenidos fundamentales, sus articulaciones especificas, el estilo singular y la pedagogía propia. Acoger con alegría y disponibilidad este don de la gracia exige hacerlo fecundo a través de elecciones de vida concretas y coherentes.

$Y$ es fundamental que tengamos en cuenta que no son nuestros méritos los que inclinan a Dios, sino el amor que Dios nos tiene y su preocupación, que elige mediadores para hacerse presente a los hombres. Jesús mismo nos dice: "No me habéis elegido vosotros a mí; sino que yo os he elegido yo a vosotros, y os he destinado para que vayáis y deis fruto, y que vuestro fruto permanezca; de modo que todo lo que pidáis al Padre en mi nombre os lo conceda. Lo que os mando es que os améis los unos a los otros» (Jn 15, 16-17).

Si la vocación a la alegría del amor es el llamado fundamental que Dios pone en el corazón de cada joven con vistas a que su existencia pueda dar fruto, la fe es al mismo tiempo don que viene de lo alto y respuesta al sentirse elegidos y amados. La fe, en este sentido, «no es un refugio para gente pusilánime, sino que ensancha la vida. Hace descubrir una gran llamada, la vocación al amor, y asegura que este amor es digno de fe, que vale la pena ponerse en sus manos, porque está fundado en la fidelidad de Dios, más fuerte que todas nuestras debilidades» (Lumen fidei 53). Esta fe «ilumina todas las relaciones sociales», contribuyendo de esta manera a «construir la fraternidad universal» entre los hombres y las mujeres de todos los tiempos (ibid., 54).

Esta llamada que pone en el corazón de los jóvenes el amor no es una llamada a retirarse a un lugar seguro, sino a salir al encuentro de los hermanos necesitados, a mostrar la novedad del Evangelio, a poner el lenguaje nuevo de comunicación de la Palabra, ese lenguaje que está más en la 
contemplación de quien es la Palabra viva entre nosotros, Jesús y su misterio de redención, que de muchos y sesudos discursos. No puede ser nunca una palabra que se lleva el viento, porque está asentada en la misma eterna consistencia amorosa de Dios-Padre que nos ama tanto que no quiere vivir sin nosotros. Por eso toda llamada de Dios debe estar, y en principio lo está, al servicio del Amor traducido en amor cercano, ese amor que nos lleva a construir la fraternidad universal, ese ámbito en el que todo hermano se siente como en casa.

\section{DISCERNIR}

No es esta llamada de Dios una ilusión, ni una aparición, porque Dios habla a través de los acontecimientos y nos permite discernir, o sea, saber elegir aquello para lo que nos llama, con la seguridad de que en ese camino desarrollaremos nuestra vida y alcanzaremos la felicidad. Esto no exime de momentos difíciles, de errores, porque en el camino también surgen dificultades. El documento sinodal ofrece tres verbos, citando Evangelii gaudium 51: reconocer, interpretar y elegir.

\section{a) Reconocer}

«El reconocimiento se refiere, en primer lugar, a los efectos que los acontecimientos de mi vida, las personas que encuentro, las palabras que escucho o que leo producen en mi interioridad una variedad de 'deseos, sentimientos, emociones'». Yo me encuentro en la encrucijada con una serie de sentimientos, en muchos casos contradictorios. No tengo seguridad alguna de qué dirección debo tomar, la lucha interior es fuerte y tengo que situarme en actitud de reconocer lo que esto está significando en mi persona y dejarme iluminar.

El documento nos lo dice con claridad. La luz que hemos de poner es la Palabra de Dios. Desde ella se encuentra el foco de mi verdad de vida.

En esta fase, la Palabra de Dios reviste una gran importancia: meditarla, de hecho, pone en movimiento las pasiones como todas las experiencias de contacto con la propia interioridad, pero al mismo tiempo ofrece una posibilidad de hacerlas emerger identificándose con los acontecimientos que ella narra. La fase del reconocimiento sitúa en el centro la capacidad de escuchar y la afectividad de la persona, sin eludir por temor la fatiga del silencio. Se trata de un paso fundamental en el camino de maduración personal, en particular para los jóvenes que experimentan con mayor intensidad la fuerza de los deseos y pueden también permanecer asustados, renunciando incluso a los grandes pasos a los que sin embargo se sienten impulsados. 
Nuestro ángulo de visión puede estar deformado por el miedo, la inseguridad, la valoración objetiva de lo que se me pide y lo que creo que puedo dar... Es preciso entonces que maduremos, que no sean las impresiones lo que nos lleve a una decisión, sino la acción de la Palabra escuchada y meditada. También es importante que nos fijemos en aquellos que han decidido y el grado de identificación que promueven en nosotros. Reconocer, saber que esto que surge en mí tiene el origen en Alguien que vela y se me hace el encontradizo a través de los acontecimientos de la vida.

\section{b) Interpretar}

Si el primer paso es reconocer (saber qué) no ganaríamos nada si no nos esforzamos en interpretar qué significa. El texto citado más abajo nos habla de lo que significa abrirse a esa interpretación o lo que nos lleva a cerrarnos en nuestro yo egocéntrico. Sin admitir voz alguna que interpele y haga salir de uno mismo.

No basta reconocer lo que se ha experimentado: hay que «interpretarlo», o, en otras palabras, comprender a qué el Espíritu está llamando a través de lo que suscita en cada uno. Muchas veces nos detenemos a contar una experiencia, subrayando que «me ha impresionado mucho». Más difícil es entender el origen y el sentido de los deseos y de las emociones experimentadas y evaluar si nos están orientando en una dirección constructiva o si por el contrario nos están llevando a replegarnos sobre nosotros mismos.

La mayor dificultad para acertar en esta interpretación es dejarse llevar por impresiones egoístas, por emociones no controladas, por falsos arranques de pietismo o deseos viscerales. Una cosa es que nuestros sentimientos estén concordes con la llamada y otra que el elemento emocional nos anule la capacidad de reflexión. Uno se pregunta por la razón de que muchas llamadas del Señor (a cualquier modalidad vocacional: compromiso laical, vida religiosa, sacerdocio...) no son escuchadas y, por lo tanto, respondidas; la contestación puede venir o por la falta de escucha. De ámbito de reflexión, de paciencia, de entorno favorable o, al menos, no contrario.

Hemos de ser capaces de darnos cuenta de los efectos de los condicionamientos sociales y psicológicos. También exige poner en práctica las propias facultades intelectuales, sin caer sin embargo en el peligro de construir teorías abstractas sobre lo que sería bueno o bonito hacer: también en el discernimiento «la realidad es superior a la idea».

Desde esta llamada a la realidad es importante situarnos con total apertura ante las circunstancias concretas. Como dice el texto, no valen teorías 
sobre lo que sería bueno; es preciso que calibremos los signos reales que nos llevan a inclinarnos por un camino u otro. Ayuda la inteligencia y además puede poner «en orden» los sentimientos, a veces exaltados. El movimiento de nuestros impulsos o afectos ha de ser controlado. Sabemos bien a lo que lleva el actuar por impresiones, irreflexivamente, por efecto de las circunstancias externas, por influencia de la realidad que nos rodea, por influjo de lo socialmente correcto. Sin embargo, es necesario saber elegir el camino que Dios nos propone. Sólo él es camino de realización en la vida.

Y, como nos señala el último párrafo de este apartado: «Este trabajo de interpretación se desarrolla en un diálogo interior con el Señor, con la activación de todas las capacidades de la persona; la ayuda de una persona experta en la escucha del Espíritu es, sin embargo, un valioso apoyo que la Iglesia ofrece, y del que sería poco sensato no hacer uso».

\section{c) Elegir}

Después de la interpretación viene la elección. Pero siempre desde la libertad, sin coacción o mediatización. Hay que hacerlo desde la serenidad y la confianza.

Una vez reconocido e interpretado el mundo de los deseos y de las pasiones, el acto de decidir se convierte en ejercicio de auténtica libertad humana y de responsabilidad personal, siempre claramente situadas y por lo tanto limitadas. Entonces, la elección escapa a la fuerza ciega de las pulsiones, a las que un cierto relativismo contemporáneo termina por asignar el rol de criterio último, aprisionando a la persona en la volubilidad. Al mismo tiempo se libera de la sujeción a instancias externas a la persona y, por tanto, heterónomas, exigiendo asimismo una coherencia de vida.

La necesidad de un ambiente de silencio y escucha en la oración al Señor resulta imprescindible. Aun teniendo en cuenta que los elementos exteriores tienen su influencia, es desde el yo libre y en tensión de escucha de la palabra de Dios el que acierta o yerra al elegir, sobre todo si no se ha liberado (difícil siempre) de los pesos muertos que el tono social impone. La elección se hace en el ahora histórico, no puede ser nunca desde la nostalgia de otros tiempos «mejores» (o así percibidos), sino en la convicción de que nuestra tarea es para este mundo actual, para esta sociedad, que es la que necesita evolucionar en valores. Lo verdaderamente importante es responder en el aquí y ahora con la perspectiva puesta en el futuro. $Y$ es cada uno el que toma esas decisiones:

Promover elecciones verdaderamente libres y responsables, despojándose de toda connivencia con legados de otros tiempos, sigue siendo el objetivo de 
toda pastoral vocacional seria. El discernimiento es en la pastoral vocacional el instrumento fundamental, que permite salvaguardar el espacio inviolable de la conciencia, sin pretender sustituirla (cf. Amoris laetitia 37).

En consecuencia, la realidad es la que finalmente debe marcar el camino de la decisión vocacional. A este respecto leemos:

La decisión debe ser sometida a la prueba de los hechos en vista de su confirmación. La elección no puede quedar aprisionada en una interioridad que corre el riesgo de mantenerse virtual o poco realista -se trata de un peligro acentuado en la cultura contemporánea-, sino que está llamada a traducirse en acción, a tomar cuerpo, a iniciar un camino, aceptando el riesgo de confrontarse con la realidad que había puesto en movimiento deseos y emociones. Otros movimientos interiores nacerán en esta fase: reconocerlos e interpretarlos permitirá confirmar la bondad de la decisión tomada o aconsejará revisarla. Por esto es importante «salir», incluso del miedo de equivocarse que, como hemos visto, puede llegar a ser paralizante.

\section{CAMINOS DE VOCACIÓN Y MISIÓN ${ }^{1}$}

\section{a) Etapas del discernimiento}

Está claro que en camino del discernimiento vocacional son varias las etapas que se dan. Dentro de ellas hay momentos que son cruciales, lugares interiores que se hacen notar en las decisiones que se van progresivamente tomando. En realidad, algunas etapas están bien estudiadas y podemos citarlas para que nos hagan más sencilla la tarea de discernir junto al sujeto a quien se acompaña:

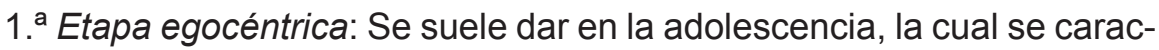
teriza por los cambios y la crisis, aunque el origen de la adolescencia es la etapa fisiológica, influye también en las actitudes y las conductas.

Algunas características: conciencia de las nuevas energías (ansiedad, variabilidad); necesidad de autoafirmación (independencia, libertad); necesidad de autonomía, de juicio personal, de elección; amor y repliegue sobre sí mismo (ve a los demás sólo en función del efecto que le producen); incapacidad de percibir el subjetivismo de sus apreciaciones.

El egocentrismo es en el adolescente un mecanismo de defensa normal, debido al conflicto entre las fuerzas interiores de crecimiento que le empujan a la autoafirmación y a las fuerzas exteriores (padres, educadores...) que le empujan a replegarse sobre sí mismo.

1. Todo lo que sigue se ha tomado de los materiales usados en Instituto Vocacional «Maestro Ávila», perteneciente a la Hermandad de Sacerdotes Operarios diocesanos. 
Criterio de intervención pedagógica. El discernimiento en esta etapa, prevalentemente egocéntrica, ha de situarse en el paso que el sujeto está dispuesto a dar y ayudarle para que no se equivoque. Pese al egocentrismo hay un alto valor de generosidad en muchos adolescentes y, si descubren un posible camino real, se esfuerzan por abrirse al acompañante.

2. ' Etapa de idealización: Se comienza a establecer relaciones con el exterior sobre nuevas bases. Su realidad personal la considera penosa y siente que tiene que forjarse un personaje ideal que sea su modelo, se abre a más posibilidades le lleva a soñar con el personaje ideal que le gustaría ser. Importante para el discernimiento es que elija un modelo de identificación que le libere de las corrientes negativas de la sociedad en la que vive, porque ese modelo le ayuda a cambiar: desde el realismo de asumir el "ahora soy así», está preparado para con un «puedo ser parecido a quien es mi modelo», ir superándose a sí mismo y llegar a la preparación de la madurez. No es negativo que busque imitar-identificarse con él/ellos, porque le parece que tienen «poderes» o «cualidades» que a él le faltan. Se fabrica «ídolos». El ídolo le libera de la inseguridad, agresividad, frustraciones. Pero ¡cuidado! Si se convierten en ídolos de verdad pueden perder el sentido de lo que son y permanecer tiempo en ese estadio. Se relaciona con los otros en cuanto los necesita o responden a sus «ideales». Amar al otro es amar-admirar los aspectos idealizados de él. No se percibe la totalidad de la persona.

Criterio de intervención pedagógica. La necesidad de imitar, ser como otro, puede ser medio de crecimiento en la medida en que permite romper el caparazón y el repliegue sobre sí.

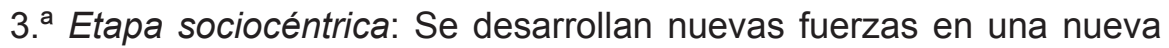
dirección: hacia fuera. Descubre que puede ser feliz haciendo feliz al que ama, y aun haciendo renuncias. Percibe que puede desarrollar sus capacidades para ponerlas al servicio de los otros y ejercer un papel en la sociedad. Puede llegar a percibir al otro objetivamente, amarle como es y no sólo como él lo sueña.

Criterio de intervención pedagógica. En esta etapa la capacidad de discernir con generosidad aumenta, ya que su percepción va más allá de lo que a él le ocurre y se sitúa a las expectativas de qué puede hacer por los otros, sin auto referencias del qué me puede dar a mí esa persona. Liberado de los que supone el idealizar como falsedad de lo que yo soy, la luz del camino a seguir se hace más nítida. Pero teniendo en cuenta que el discernimiento es una forma de vivir que no cesa, sino que es un estado de vida para poder progresar en humanidad y no quedar «detenido en el tiempo». 
b) Etapas de la vocación

1. La emoción privilegiada: La vocación se asocia o se identifica con una emoción especial (lectura, encuentro...). La emoción es leída como señal vocacional.

2. El deseo de imitar un modelo: Los modelos son mediaciones ordinarias y necesarias en el descubrimiento y respuesta vocacional.

3. La elección de una función vocacional que compromete: La respuesta vocacional se manifiesta en la elección de una función y/o forma de vida por los valores que progresivamente se descubren en ellos.

Estas etapas de la vocación se inscriben en las etapas psicológicas de aprendizaje del amor, y se perciben e interpretan de modos muy diferentes según la etapa psicológica desde la que se vivan.

Si cruzamos las dos variables (etapas psicológicas y etapas de la vocación) obtenemos un patrón que nos sirve de guía para realizar un primer discernimiento y saber con qué grado de madurez está viviendo la persona su momento en el proceso vocacional.

El discernimiento vocacional no se realiza en un acto puntual, aun cuando en la historia de cada vocación es posible identificar momentos o encuentros decisivos. Como todas las cosas importantes de la vida, también el discernimiento vocacional es un proceso largo, que se desarrolla en el tiempo, durante el cual es necesario mantener la atención a las indicaciones con las que el Señor precisa y específica una vocación que es exclusivamente personal e irrepetible.

Como nos dice el documento: «María misma progresa en la conciencia de su vocación a través de la meditación de las palabras que escucha y los eventos que le suceden, también los que no comprende (cf. Lc 2, 50-51)».

El mismo Jesús se va haciendo progresivamente consciente de cuál es su misión. Ciertamente él no necesita discernimiento, pero sí toma conciencia de que aquello que hace y dice es "porque se lo ha oído a su Padre» y quiere comunicarla a sus discípulos que, solamente tras la resurrección entienden bien la misión del Maestro, que a ellos se les encomienda. Posiblemente uno de los ejemplos del largo proceso de discernimiento sea el de los apóstoles. Ellos siguen a Jesús, fundamentalmente, porque su persona les atrae y piensan que va a ser ese mesías que libere al pueblo del dominio romano. Muchas de las preguntas que le hacen siguen en esta convicción: "¿Es ahora cuando vas a establecer tu reino?».

El tiempo es fundamental para verificar la orientación efectiva de la decisión tomada. Como enseña cada página del texto bíblico, no hay vocación que no se ordene a una misión acogida con temor o con entusiasmo. 
Cierto que las ganancias del decir sí al proyecto de Dios sobre cada uno de nosotros no son visibles y suponen un riesgo. Nos basta con mirar no sólo las persecuciones del pasado histórico, sino las de nuestra época, para darnos cuenta de que seguir el camino de Jesús supone «arriesgar la propia vida y recorrer la vía de la cruz... para ofrecer su vida por la humanidad». Y en una sociedad como la nuestra, marcada por el individualismo, necesitamos discernir bien las motivaciones de la elección: «Es necesario verificar hasta qué punto las elecciones son dictadas por la búsqueda de la propia autorrealización narcisista y en qué grado, por el contrario, incluyen la disponibilidad a vivir la propia existencia en la lógica de la generosa entrega».

4. El acompañamiento: Más arriba decíamos que se acompaña para ayudar a discernir, pero es necesario acompañar a la persona en su contexto vital. De ahí las tres convicciones que señala el documento:

La primera es que el Espíritu de Dios actúa en el corazón de cada hombre y de cada mujer a través de sentimientos y deseos que se conectan a ideas, imágenes y proyectos. Escuchando con atención, el ser humano tiene la posibilidad de interpretar estas señales. La segunda convicción es que el corazón humano, debido a su debilidad y al pecado, se presenta normalmente divido a causa de la atracción de reclamos diferentes, o incluso opuestos. La tercera convicción es que, en cualquier caso, el camino de la vida impone decidir, porque no se puede permanecer indefinidamente en la indeterminación. Pero es necesario dotarse de los instrumentos para reconocer la llamada del Señor a la alegría del amor y elegir responder a ella.

Para lograr la elección, hay que emplear una serie de instrumentos entre los cuales está el acompañamiento. Y este es muy importante, porque no se trata de hacer un estudio psicológico de la persona acompañada, al menos no sólo, sino ante todo ser: saber escuchar, descubrir los momentos difíciles por los que pasa para ponerle sencillo el que se abra con confianza al acompañante, interpretar la acción del Espíritu.

Hay muchos textos en la Escritura en los que se presenta el modo de acompañar -un buen ejemplo es el relato de los discípulos de Emaús (Lc $24,13-35)$ - y que evocan las cualidades que ha de tener el acompañante.

En general, nos invita a releer la realidad que nos ocupa, preocupa y rodea. Hay algunos signos. Es un camino. Los discípulos están en marcha. No se han quedado quietos, pero ¿qué hacen? Se alejan.

En el camino hay un proceso por etapas:

-Un punto de partida: La sentida ausencia de Jesús. Sus comentarios van en la línea de que poco menos que los ha engañado y abandonado. Sienten el tedio, la sinrazón de unos años en los que lo habían dejado todo... 
para nada. Les duele esa situación, porque ha sido a ellos a los que se les ha hecho cierto fraude. Están heridos en sus sentimientos. Se miran hacia dentro. Y se hacen muchas preguntas: ¿por qué ha sucedió esto?, ¿qué razones había para que lo mataran? Si no era quien decía ser, ¿por qué nos ha engatusado para que le acompañemos? ¿Y ahora qué?

-Un encuentro: Quizás en principio es más una incorporación que un encuentro: alguien se les une en el camino. Pero ellos no están para muchas identificaciones. De todas maneras... se ha interesado por ellos, habrá que enseñarle, contarle los sucesos de los que parece no haberse enterado. De momento, se detienen, entristecidos, pero se detienen: algo es algo. En principio increpan al viajero, porque no se entera. Y el viajero se muestra propicio a escuchar su problema, su situación, el motivo de esas caras tan largas.

-Una pedagogía puesta en marcha: Jesús les hace descubrir que la realidad es otra. Que no es cierto que su esperanza se haya visto defraudada. No han entendido. La lectura de los hechos es muy otra: precisamente lo sucedido muestra el que se han llevado a cabo las esperanzas que tenían, que nada ha sucedido que esté fuera del contenido y la finalidad de la «promesa de salvación». Ocurre que no han entendido qué salvación da el Padre a través del Hijo. Como detalle su desprecio hacia la credibilidad que tenían las mujeres y su no total confianza en el testimonio de los que habían ido al sepulcro. La ceguera es manifiesta.

- Jesús acompañante: Sorprende la manera como se hace con ellos y pasa de informado a maestro. Les enseña lo que estaba escrito y no habían sabido leer. Hace el camino con ellos, no les invita a modificarlo forzados por nada, ni les hace reconvención alguna. Les hace ver. Cuando quiere seguir adelante, ellos le invitan. Siempre he pensado que sólo cuando empiezan a descubrirlo en su interior están preparados para encontrarse con él.

-El encuentro: Se produce en torno a la mesa, al partir el pan. Compartiendo. Las dudas, el dolor del abandono, los titubeos, las alegrías del camino. Ha habido un proceso de reencuentro cuando notaban (aunque lo manifiesten al final) que su corazón ardía. La vuelta a donde está la comunidad es también muy significativa del modo como debemos hacer la evangelización y de suscitar nuevas vocaciones.

\section{c) Aplicaciones}

Estamos en un momento en el que han desaparecido muchos de los signos (con significado) que daban seguridad a nuestra tarea pastoral, que hacían fácil el que alguno de los niños o jóvenes de nuestro entorno dijera que quería ser como nosotros: la nota de felicidad, de vida plena, de satisfacción 
por el ministerio, de prestigio social del sacerdote, eran motivaciones para la respuesta, eran mediaciones. Jesús estaba realmente presente. Ahora, ante el cambio de circunstancias y la pobreza vocacional, experimentamos la perplejidad.

Sin embargo, las cosas cambian si nos dejamos acompañar por Jesús y le descubrimos: su modo no es impositivo, simplemente nos acompaña y, al ritmo de ese caminar, va haciendo que le descubramos. Se pone en nuestro lugar y nos conduce hacia donde debemos ir. 